\title{
Hernia diafragmatică dreaptă - un diagnostic de avut în vedere
}

\author{
Ruxandra Darie', Raluca Maria Vlad ${ }^{1,2}$ \\ ${ }^{1}$ Spitalul Clinic de Urgenţă pentru Copii „Grigore Alexandrescu“, Bucureşti, România \\ 2Universitatea de Medicină şi Farmacie "Carol Davila“, Bucureşti, România
}

\begin{abstract}
REZUMAT
Obiective. Hernia diafragmatică nu este o patologie comună. Severitatea simptomelor depinde de dimensiunea defectului. Localizarea dreaptă este foarte rară. Această afecţiune congenitală poate fi inaparentă clinic o lungă perioadă de timp.

Material şi metodă. Autorii prezintă cazul unei paciente internate în Departamentul Pediatrie al Spitalului „Grigore Alexandrescu“ pentru patologie respiratorie acută, diagnosticată întâmplător cu hernie diafragmatică dreaptă după vârsta de trei ani.

Rezultate (prezentare de caz). Pacientă în vârstă de 3 anişi 6 luni se internează pentru tuse persistentă. Intrauterin, fusese diagnosticată cu agenezie de arc aortic. S-a născut prematur, a necesitat terapie intensivă în perioada neonatală, unul dintre diagnosticele stabilite fiind hemoragie pulmonară dreaptă. Ecografia efectuată postnatal a pus diagnosticul de anomalie de duct venos. Evoluţia clinică a fost bună, cu funcţii cardiacă şi hepatică normale, parametri auxologici normali pentru vârstă. Examenul clinic nu a evidenţiat elemente patologice, cu excepţia tusei. Radiografia toracică a descris o opacitate bine delimitată, omogenă, la nivelul lobului pulmonar drept. Ecografia abdominală a confirmat continuarea azygos a venei cave inferioare. A primit antibioticoterapie pentru pneumonie acută $(7$ zile) cu menţinerea neschimbată a imaginii radiologice. Tomografia computerizată toracică a evidenţiat prezenţa unei hernii diafragmatice Morgagni cu translocarea ficatului la nivel toracic.

Concluzii. Hernia diafragmatică este un diagnostic dificil. Deşi afecţiune congenitală, poate fi asimptomatică o lungă perioadă de timp şi un înalt grad de suspiciune este necesar pentru diagnostic.
\end{abstract}

Cuvinte cheie: hernie diafragmatică, copil, Morgagni

\section{Abrevieri}

HDC: Hernia diafragmatică congenitală

HDCD: Hernia diafragmatică congenitală dreaptă (Morgagni)

\section{INTRODUCERE}

Hernia diafragmatică congenitală (HDC) reprezintă un defect în dezvoltarea muşchiului diafragm, fenomen ce determină protruzia viscerelor abdominale în cavitatea toracică şi împiedică dezvoltarea normală a plămânilor. Afecţiunea se poate prezenta în două variante: absenţa completă a diafragmului/ deficit de substanţă la nivelul acestuia din cauza unei anomalii embriologice de formare sau ,muscularizarea“ deficitară cu eventraţii $(1,2)$. Patologia are o uşoară predispoziţie pentru sexul masculin, însă, în ceea ce priveşte hernia diafragmatică dreaptă Morgagni (HDCD), nu există date care susţin predilecţia de gen (3).

HDC se poate prezenta ca o afecţiune izolată sau aparţinând unui sindrom. $2 \%$ din totalul cazuri- lor au fost raportate ca forme familiale de boală, transmiterea realizându-se pe cale autozomal dominantă, recesivă sau x-linkată. Sindromul Fryns este o afecţiune autozomal recesivă care se caracterizează prin HDC, anomalii cerebrale, cardiace, urinare şi hipoplazie a falangelor distale. Sindromul Cornelia de Lange este o boală genetică cu transmitere autozomal dominantă, ce include HDC, hirsutism şi retard în dezvoltare. Cele mai frecvente anomalii cromozomiale asociate cu HDC sunt trisomia 13,18 sau $21(2,4)$.

Etiologia nu este complet elucidată, dar se presupune a fi multifactorială. Există numeroşi factori genetici, nutriţionali şi de mediu implicaţi în apariţia HDC, printre care se numără defecte genetice în calea de metabolizare a vitaminei A, deficit de reti- 
nol/proteine transportoare de retinol sau expunerea la ierbicide (2).

Muşchiul diafragm se formează între săptămânile 8 și 12 de gestaţie. Cavităţile toracică și abdominală sunt separate de o structură fibroasă, numită septum transversum, care mai târziu, în decursul vieţii intrauterine, va fi populată de fibre musculare. HDC se caracterizează prin migraţia viscerelor din abdomen în cavitatea toracică, fenomen ce conduce la apariţia hipoplaziei pulmonare, principala complicaţie a acestei patologii $(4,5)$.

Defectele localizate pe partea stângă sunt mai frecvente $(85 \%$ din totalul cazurilor) şi sunt de regulă asociate cu hernierea stomacului, intestinului, ficatului sau splinei în cavitatea toracică. Acestea poartă numele de hernii Bochdalek (posterolaterale). Herniile non-posterolaterale reprezintă defecte anterioare ale diafragmei şi pot să apară pe partea dreaptă, stângă sau pe linia mediană. Hernia Morgagni-Larrey afectează aproximativ 2\% din populaţia de nou-născuţi, este localizată pe partea dreaptă şi se caracterizează prin protruzia ficatului şi/sau a intestinului în cavitatea toracică. Printre alte defecte situate anterior $(2-7 \%)$ se numără Pentalogia lui Cantrell (HDC, malformaţii cardiace), o formă severă de hernie diafragmatică, şi hernia centrală (o patologie rară care implică porţiunea non-musculară a diafragmului) $(1,6)$.

Hernia Morgagni are întotdeauna un sac herniar format din peritoneu parietal sau diafragm hipoplazic. Majoritatea cazurilor sunt asociate cu multiple malformaţii sau defecte cromozomiale: malrotaţii intestinale, defect de sept ventricular, stenoză de arteră pulmonară, sindrom Down. În majoritatea cazurilor de HDCD, diagnosticul se stabileşte la vârsta de adult, rareori la vârstă pediatrică. Aceşti pacienţi prezintă rar la debut complicaţii de tip obstrucţie intestinală sau încarcerare. Diagnosticul în acest caz este suspicionat pe baza unei radiografii abdominale pe gol şi este confirmat de examenul CT. Diagnosticul diferenţial al HDC include: chistul bronhogenic, teratomul chistic, agenezia pulmonară (3).

\section{PREZENTARE DE CAZ}

Pacientă în vârstă de 3 ani şi 6 luni se internează pentru tuse productivă persistentă. Din anamneză reţinem infecţii recurente de tract respirator superior în ultimele 6 săptămâni (după intrarea în colectivitate), cu scurte perioade de ameliorare sub tratament simptomatic. $\mathrm{Cu} 4$ zile anterior internării a prezentat accese frecvente de tuse productivă şi dispnee, fără altă simptomatologie asociată.
În trimestrul II de sarcină, s-a ridicat suspiciunea unei malformaţii cardiace incompatibile cu viaţa (agenezie de arc aortic), infirmată ulterior. Întrucât a dezvoltat ascită intrauterină, s-au pus în balanţă complicaţiile obstetricale versus riscurile prematurităţii şi s-a decis extragerea fătului prin operaţie cezariană la 33 săptămâni de gestaţie (scor APGAR =6-7). A necesitat reanimare neonatală şi terapie intensivă, unul dintre diagnostice fiind hemoragie pulmonară dreaptă (fig. 1). Ecografia abdominală şi ecocardiografia postnatală au evidenţiat malformaţie venoasă complexă (anomalie de duct venos şi vene suprahepatice cu deschidere separată în atriul drept), cardiomiopatie hipertrofică uşoară şi ascită.

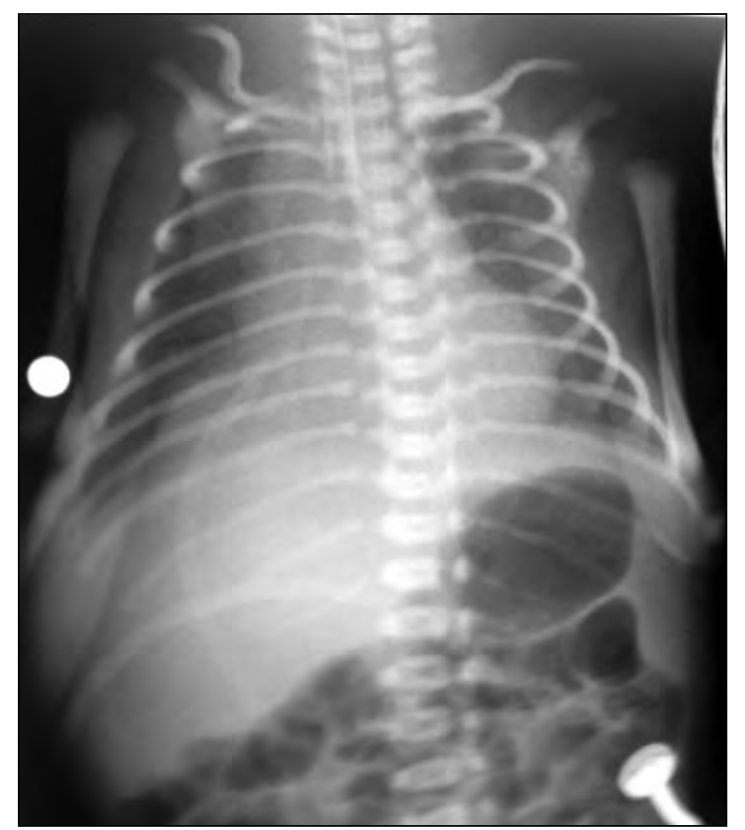

FIGURA 1. Radiografie toracică din perioada neonatală: pacienta a fost diagnosticată cu hemoragie pulmonară

În primii trei ani de viaţă, evoluţia clinică a fost bună, cu funcţii cardiacă şi hepatică normale, parametri auxologici normali pentru vârstă.

Examenul clinic la internare a relevat ca unic simptom tusea productivă, cu o frecvenţă respiratorie 24/minut, $\mathrm{SaO}_{2}$ în aerul atmosferic $99 \%$ şi frecvenţa cardiacă 80 /minut. S-au evidenţiat hemangioame cavernoase la nivelul scalpului şi toracelui anterior.

Hemograma a evidenţiat hemoglobină normală, 19.100 leucocite $/ \mathrm{mm}^{3}$, cu formula leucocitară normală, şi 320.000 trombocite $/ \mathrm{mm}^{3}$. Nu a prezentat sindrom biologic inflamator. Imunograma, funcţia hepatică şi renală au fost în limite normale. Exsudatele nazal şi faringian, lavajul gastric pentru bacilli acid-alcool rezistenţi, IDR la PPD şi aspiratul traheo-bronşic au fost negative. 
Radiografia toracică a evidenţiat opacitate omogenă, bine delimitată, de intensitate subcostală, care şterge conturul drept al cordului (fig. 2).

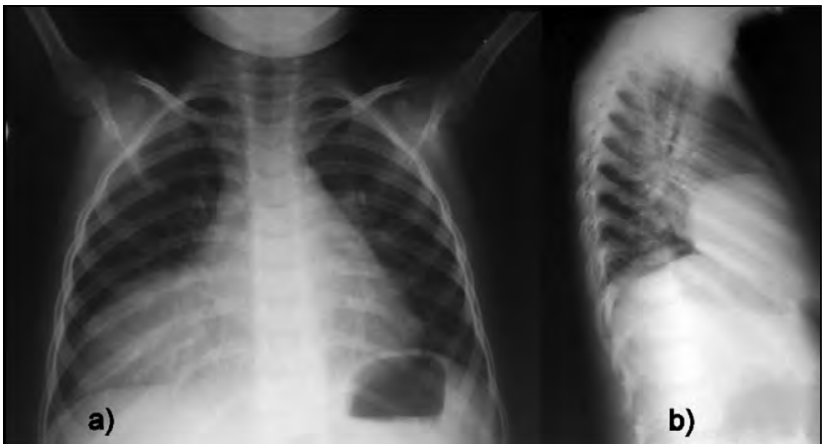

FIGURA 2. Radiografie toracică: (a) postero-anterioară,

(b) profil drept

Ecografia abdominală a descris o malformaţie venoasă complexă (vena suprahepatică stângă drenează în atriul drept, iar vena suprahepatică dreaptă se deschide în vena cavă). Ecocardiografia a susţinut prezenţa unei anomalii de duct venos (continuare azygos a venei cave inferioare).

Coroborând examenul clinic, investigaţiile biologice şi imagistice, s-au stabilit diagnosticele: pneumonie de lob mediu, malformaţie venoasă complexă şi hemangioame cavernoase la nivelul scalpului şi toracelui.

S-a instituit terapie antibiotică timp de 7 zile cu ameliorare clinică, dar cu persistenţa imaginii radiologice. Din acest motiv, au fost luate în discuţie multiple diagnostice diferenţiale (malformaţie de căi aeriene, formaţiune tumorală) şi s-a decis efectuarea CT toracic, care a stabilit diagnosticul de hernie diafragmatică dreaptă (tip Morgagni) cu protruzia ficatului în cavitatea toracică (fig. 3).

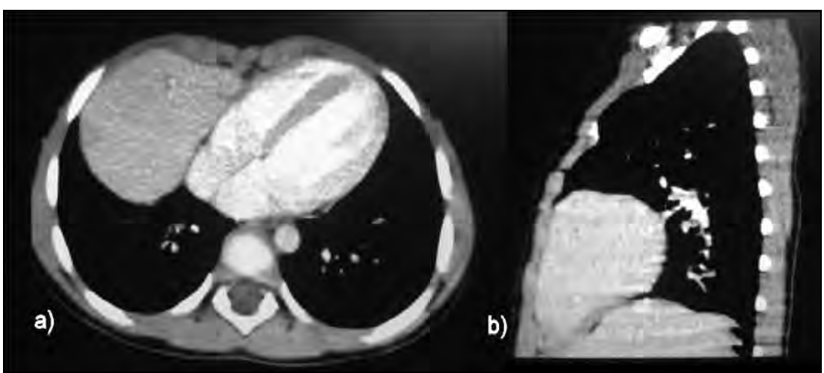

FIGURA 3. CT torace (a) sectiune transversal, (b) secțiune sagitală

S-a efectuat irigografie care a infirmat prezenţa unei anse intestinale la nivel toracic (fig. 4).

La acest moment, consultul chirurgical a exclus riscul de ocluzie intestinală şi a decis temporizarea unei intervenţii. Opţiunea unei terapii chirurgicale a fost luată din nou în discuţie 3 ani mai târziu şi s-a

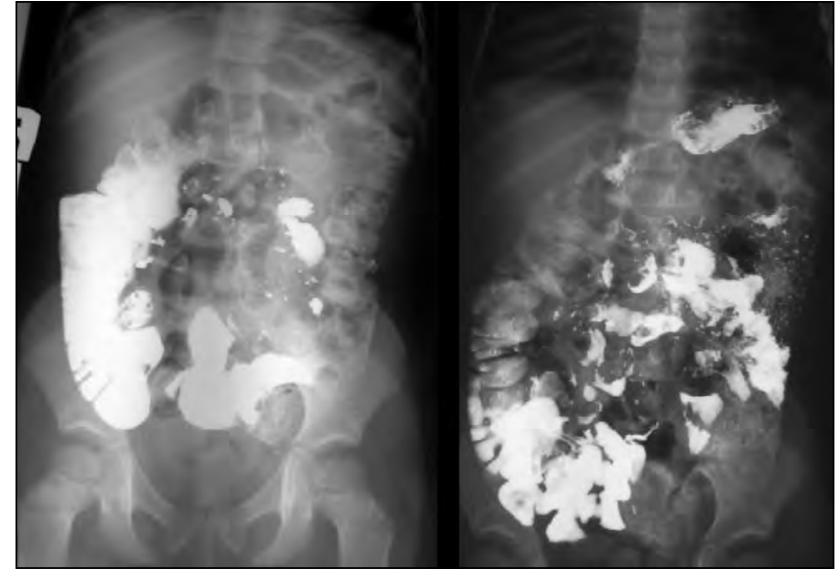

FIGURA 4. Irigografie: nu se evidențiază anse intestinale la nivelul toracelui

stabilit indicaţia de corecţie a defectului cu repoziţionarea ficatului intraabdominal, întrucât pacienta a început sa dezvolte semne de hipertensiune pulmonară.

\section{DISCUTุII}

Cea mai frecventă manifestare clinică de debut a herniei diafragmatice congenitale este detresa respiratorie (cianoză, tiraj inter/subcostal, geamăt expirator). Semnele clinice sunt evidente în primele 24 de ore postnatal ca urmare a hipoplaziei pulmonare, care apare de regulă ipsilateral cu HDC. Cu toate acestea, există forme de hernie diafragmatică, cum ar fi hernia tip Morgagni, care sunt asimptomatice în perioada neonatală. În cazul de faţă, pacienta a necesitat terapie intensivă neonatală, fiind născută prematur. Opacitatea vizualizată la acel moment la nivelul câmpului pulmonar drept a fost interpretată drept hemoragie pulmonară; comparând cele două imagini (fig. 1 şi 2a), similaritatea este evidentă. Alte caracteristici clinice ale HDC sunt: abdomen scafoid, torace în formă de butoi, borborisme intestinale la auscultaţia pulmonară şi tahicardie. În HDC asociată sindroamelor genetice se pot identifica dismorfisme cranio-faciale, disrafie spinală sau malformaţii ale extremităţilor $(1,7,8)$. Nici unul dintre aceste semne clinice nu a fost descris la pacienta prezentată.

Până la o treime dintre cazurile de hernie Morgagni sunt raportate ca fiind asimptomatice, în ciuda caracterului congenital al afecţiunii. Forme de debut ale bolii includ infecţii recurente de tract respirator, simptomatologie gastro-intestinală sau acuze nespecifice. Afectarea gastro-intestinală este rară, iar atunci când apare are de obicei caracter obstructiv din cauza încarcerării anselor intestinale (mai ales a colonului) în sacul herniar $(3,8)$. În ca- 
zul de faţă, diagnosticul a fost stabilit întâmplător, când pacienta introdusă recent în colectivitate a dezvoltat simptome respiratorii persistente şi s-a considerat necesară efectuarea unei radiografii pulmonare.

Printre complicaţiile HDC se numără: hipertensiunea pulmonară, disfuncţia de ventricul stâng, boala pulmonară cronică, refluxul gastroesofagian sau hipoplazie intestinală. Majoritatea copiilor cu afecţiuni pulmonare severe prezintă eşecul creşterii şi retard în dezvoltarea psiho-motorie (7). Pacienta noastră nu a dezvoltat complicaţii până la vârsta de 6 ani. În momentul în care au apărut semne de hipertensiune pulmonară, atitudinea chirurgicală s-a schimbat radical.

O complicaţie redutabilă şi extrem de rară, ce apare în herniile localizate pe partea dreaptă (doar 14 cazuri citate în literatură, majoritatea cu debut neonatal), este fuziunea hepato-pulmonară. Alipirea ţesutului hepatic la pleură prin intermediul unei benzi fibroase, fistula bronho-biliară sau drenajul aberant din plămânul drept la nivelul venei cave inferioare sunt doar câteva dintre anomaliile întâlnite în cadrul acestei entităţi (9).

Screening-ul prenatal de trimestru II detectează aproximativ $60 \%$ dintre herniile diafragmatice drepte şi $80 \%$ dintre cele stângi. Ecografia pelvină efectuată de rutină pe parcursul sarcinii sau în cazul investigaţiilor pentru polihidramnios (ce poate complica, conform studiilor, până la $80 \%$ dintre sarcinile cu feţi diagnosticaţi cu HDC) reprezintă principala metodă de diagnostic. IRM-ul este util în a detecta leziunile toracice atipice sau pentru a cuantifica volumul pulmonar (volumul pulmonar fetal şi cantitatea de viscere abdominale herniate în cavitatea toracică sunt principalii indicatori de prognostic). Ecografia Doppler identifică cu acuratețe herniile localizate pe partea dreaptă, dificil de evaluat prin ecografie convenţională deoarece ecogenitatea ţesutului pulmonar este similară cu cea a ţesutului hepatic. Imagistica completată cu tehnică Doppler poate demonstra hernierea ficatului în torace şi prin evidenţierea poziţiei anormale a venelor ombilicale şi a portei $(1,2,10)$. HDC a rămas nediagnosticată antenatal în cazul nostru, deşi sarcina a fost urmărită cu numeroase evaluări ecografice. Diagnosticul postnatal se bazează pe aspectele clinice - auscultaţie pulmonară diminuată ipsilateral cu poziţia herniei, deplasarea zgomotelor cardi- ace contralateral faţă de poziţia herniei -, dar şi pe cele imagistice - radiografia toracică relevă shift mediastinal sau hernierea anselor intestinale pline cu aer deasupra diafragmului (1). În acest caz, nu hernia ansă intestinală, aşadar diagnosticul a fost trecut cu vederea în repetate rânduri în perioada neonatală.

Diagnosticul tardiv se caracterizează prin prezenţa de opacităţi în câmpul pulmonar la examenul radiologic, ca în cazul prezentat, volvulus gastric sau obstrucţie intestinală. Alte aspecte identificate includ hipoplazia de ventricul stâng în herniile de parte stângă şi efuziunile pleurale în cele de parte dreaptă (6).

Managementul chirurgical poate fi realizat pe cale clasică sau prin metode minimum invazive. În majoritatea cazurilor, abordul abdominal este preferat în detrimentul toracoscopiei, mai ales dacă există anomalii asociate (ex: malformaţii cardiace). În cazul herniei diafragmatice de tip Morgagni, tratamentul chirurgical este recomandat în urgenţă amânată pentru a evita morbidităţile $(2,8)$. Deşi pacienta nu are risc de obstrucţie intestinală, alte posibile comorbidităţi asociate translocării toracice a viscerelor abdominale trebuie avute în vedere în luarea deciziei terapeutice.

Date recente din literatură au raportat o rată medie de supravieţuire pentru copiii cu hernie diafragmatică congenitală de $63 \%$. HDC izolată are în general un prognostic mai bun comparativ cu herniile asociate sindroamelor genetice cu multiple anomalii. Există trei factori predictivi majori în HDC: malformaţii asociate (în special cele cardiace), gradul hipoplaziei pulmonare şi gradul hernierii hepatice in cavitatea toracică. Independent de acest aspect, herniile situate pe partea dreaptă au o rată de mortalitate mai mare decât cele localizate pe partea stângă $(1,2,10)$.

\section{CONCLUZII}

Diagnosticul de hernie diafragmatică reprezintă o provocare pentru clinician. În ciuda caracterului congenital, afecţiunea poate rămâne asimptomatică o lungă perioadă de timp şi un înalt grad de suspiciune este necesar pentru diagnostic, mai ales în cazul herniilor localizate pe partea dreaptă, pentru care datele din literatură se bazează doar pe cazuri izolate sau serii de cazuri. 


\section{BIBLIOGRAFIE}

1. Longoni M, Pober BR, High FA. Congenital Diaphragmatic Hernia Overview. 2006 Feb 1 (Updated 2019 Mar 28). In: Adam MP, Ardinger HH, Pagon RA, et al., editors. GeneReviews ${ }^{\circledR} 2017$ (Internet). Seattle (WA): University of Washington, Seattle; 1993-2019.Available from: https://www.ncbi.nlm.nih.gov/books/NBK1359/;

2. Chandrasekharan PK, Rawat M, Madappa R et al. Congenital Diaphragmatic hernia - a review. Matern Health Neonatol Perinatol. 2017;3:6;

3. Slepov O, Kurinnyi S, Ponomarenko $O$ et al. Congenital retrosternal hernias of Morgagni: Manifestation and treatment in children. Afr J Paediatr Surg. 2016;13:57-62;

4. Sarkar A, Hajra GSD. Right Sided Congenital Diaphragmatic Hernia A Case Report With A Brief Review. J. Anat. Soc. India. 2012;61(1):53-56;

5. Almaawi A, Prasad DRK, Waqasi Z et al. Right Sided Congenital Diaphragmatic Hernia, an Operative Challenge. J Pediatr Neonatal Care. 2015;2(3):00074;
6. Sardescu G, Sbârcea A, Cîrstoveanu C. Right-sided congenital diaphragmatic hernia - case report. MEDICHUB MEDIA. Perinatologia 2017, 1(3) DOI: 10.26416/Peri.1.3.2017;

7. Boston Children's Hospital. Congenital Diaphragmatic Hernia. (Internet). http://www.childrenshospital.org/conditions-and-treatments/ conditions/c/congenital-diaphragmatic-hernia;

8. Al Shanafey S. Morgagni Diaphragmatic Hernia in Children: One Center's Experience. World Journal of Surgery and Surgical Research. 2018;1:1021;

9. Laamiri R, Belhassen S, Ksia Amina et al. Right Congenital Diaphragmatic Hernia Associated With Hepatic Pulmonary Fusion: A Case Report. J Neonatal Surg. 2016; 5(3):35;

10. Skarsgard ED, Harrison MR. Congenital Diaphragmatic Hernia: The Surgeon's Perspective. Pediatrics in Review. 1999;20(10):71-78. 